\title{
MODELING FRACTURE OF REINFORCED CONCRETE STRUCTURES UNDER IMPACT
}

\author{
Andrey Radchenko¹, Pavel Radchenko², Stanislav Batuev³, Vasiliy Plevkov ${ }^{4}$ \\ 1,2,3,4 Tomsk State University of Architecture and Building \\ 2 Solyanay Sq., Tomsk, Russia, 634003
}

${ }^{1}$ Corresponding author: andrey-radchenko@live.ru

\begin{abstract}
Introduction: The papers presents results of an integrated experimental and numerical study on behavior of reinforced-concrete beams under impulse loading. The beams under study had three layers. The upper and lower layers were of fiber-reinforced concrete with a carbon fiber volume fraction of $0.2 \%$. The middle layer was of concrete with metal reinforcement. Methods: Experimental studies were performed using a pile driver. A falling weight of $450 \mathrm{~kg}$ was dropped on a beam from a height of $0.7 \mathrm{~m}$. The authors performed numerical studies based on the finite element method in a full dynamic 3D setting, using the proprietary EFES software suite considering structure fragmentation, formation of contact and free surfaces. Results: In numerical modeling, the reinforcement mesh was clearly defined. The authors studied changes over time in the stress-strain state, and fracture of reinforced-concrete beams under short-term impact loading. They developed a calculation algorithm and procedure that made it possible to analyze and predict behavior of actual structures in a full dynamic 3D setting. They also proposed a model of concrete and fiber-reinforced concrete behavior, considering anisotropy, bimodularity with regard to strength characteristics, plastic properties, and relations between strength and strain rate / pressure. Fracture dynamics in concrete beams reinforced with metal bars was studied. Good agreement of the results with the experimental data was observed.
\end{abstract}

\section{Keywords}

Model, fracture, strain, stress, concrete, fiber-reinforced concrete.

\section{Introduction}

Describing behavior of solid bodies during their highspeed interaction is one of the most complex problems in mechanics of deformable solids. A system of equations describing dynamic behavior of deformable solids does not have an analytical solution, and it is not always appropriate to use simplified engineering approaches, especially when wave processes have a defining role. In that case, simplifying hypotheses can distort the actual state of things. Therefore, deformation and fracture of solids under impact and impulse loading are studied using mainly experimental and numerical methods.

Experiments show that final fracture of structures under impact loading is caused by a combination of mechanisms. However, they do not allow us to evaluate contribution of those fracture mechanisms at different stages of the process. After the final fracture, it is not always possible to identify fractures that occurred at the initial stages of impact interaction. Thus, mathematical modeling plays an essential role. In structure behavior analysis, mathematical modeling has some advantages over experiments: e.g. it is possible to obtain data on stresses, shock wave processes, transient processes, as well as on material and structure fracture at any specific time. A computational experiment cannot replace a physical experiment, but it can complement it. Computer development significantly extended the scope of numerical modeling application. Among the main tasks of mathematical modeling are the following: development of adequate models for behavior of materials and structures, accurately describing crack formation and fracture processes under impact and impulse loading; development of numerical methods for structural analysis that make it possible to consider actual loads taken by structures. Therefore, it is very important to perform numerical studies on behavior of concrete structures of various applications. Their practical significance lies in the fact that numerical modeling allows us to predict behavior and fracture pattern of materials and structures under dynamic loading.

Lately, non-metallic carbon-fiber or glass-fiber composite reinforcement (which is significantly anisotropic) has been used for concrete strengthening. Developing a model for behavior of materials with anisotropy under static loading is a complex and labor-intensive task. They differ from isotropic materials in a complicated internal structure depending on fiber orientation in the material, different strength characteristics along different axes, number of elastic constants (up to 21 in anisotropic materials, while only 3 in isotropic materials). Orientation of fibers relative to the loading direction, and the stress pattern significantly affect the fracture pattern in anisotropic 
materials. Under certain conditions, in different directions, fracture can be both plastic and brittle. Moreover, upon fracture of anisotropic materials (in contrast with isotropic materials), it is necessary to take into account the impact of hydrostatic pressure. Despite distinctive features, which shall be considered, anisotropic materials have a major advantage - they allow for creation of materials to be used in pre-determined conditions.

These days, anisotropic materials are widely used but their properties - especially under dynamic loading - are not sufficiently studied. Both in Russia and abroad, anisotropic materials are mainly studied in terms of static loading, and solutions are based on approximations of the theory of thin shells. What is more, they are studied both experimentally and numerically. In anisotropic materials, wave phenomena significantly affect crack formation and fracture processes, but modern engineering methods based on simplified approaches cannot demonstrate their evolution under dynamic loading. In the present paper, the authors analyze fracture of a laminated reinforcedconcrete beam. The upper and lower layers of the beam are of fiber-reinforced concrete, the middle layer is of concrete with a reinforcement mesh.

The authors perform numerical modeling based on the finite element method (Johnson, 1977; Anderson et al., 1994; Johnson, 1977) in a dynamic 3D setting, using a proprietary high-performance algorithm and software suite (Radchenko et al., 2014) implementing an algorithm of mesh generation for complex geometric objects.

\section{Basic equations of the mathematical model}

A general system of continuum mechanics equations in an arbitrary system of coordinates $(i=1,2,3)$ consists of the following equations (Sedov, 1976; Radchenko et al., 2015; Buzyurkin et al., 2015):

- mass conservation equation

$$
\frac{\partial \rho}{\partial t}+\rho \nabla_{i} v^{i}=0
$$

- motion equation

$$
\rho a^{k}=\nabla_{i} \sigma^{i k}+F^{k} \text {, }
$$

where $a^{k}=\frac{\partial v^{k}}{\partial t}+v^{i} \nabla_{i} v^{k}, \nabla_{i} \sigma^{k}=\sigma_{j}^{i k}+\Gamma_{i m}^{k} \sigma^{i m}+\Gamma_{i m}^{m} \sigma^{i k}$;

- energy equation

$$
\frac{d E}{d t}=\frac{1}{\rho} \sigma^{i j} e_{i j} \text {. }
$$

Here, $F^{k}$ - mass force vector components; $\Gamma^{k}$ - Christoffel symbols; $\sigma^{\mathrm{ij}}$ - contravariant components of the symmetric stress tensor; $E$ - specific internal energy; $\rho$-medium density; $v^{i}$ - velocity vector components; $e_{i j}$ - components of the symmetric strain rate tensor:

$$
e_{i j}=\frac{1}{2}\left(\nabla_{i} v_{j}+\nabla_{j} v_{i}\right) \text {. }
$$

Behavior of metal and concrete was described by an elastic-plastic model. The stress tensor was represented as the sum of deviatoric $S^{k i}$ and spherical $P$ components:

$$
\sigma^{i j}=-P g^{i j}+S^{i j}
$$

where $g^{i j}$ - metric tensor.

Pressure was calculated using the Mie-Grüneisen equation as a function of specific internal energy $E$ and density $\rho$ :

$$
P=\sum_{n=1}^{3} K_{n}\left(\frac{V}{V_{0}}-1\right)^{n}\left[1-K_{0}\left(\frac{V}{V_{0}}-1\right) / 2\right]+K_{0} \rho E
$$

where $K_{0}, K_{1}, K_{2}, K_{3}-$ material constants, $V_{0}-$ initial specific volume, $V$-current specific volume.

Assuming that the principle of least work of true stresses with respect to plastic incremental strains is true for the continuum, we can represent the relation between strain rate tensor and stress deviator components as follows:

$$
2 G\left(e_{i j}-\frac{1}{3} e_{k k} \delta_{i j}\right)=\frac{D S^{i j}}{D t}+\lambda S^{i j},(\lambda \geq 0)
$$

Here, time derivatives of stress tensor components, considering medium element rotation, are taken according to the Jaumann's formulation:

$$
\frac{D S^{i j}}{D t}=\frac{d S^{i j}}{d t}-S^{i k} \omega_{j k}-S^{j k} \omega_{i k}
$$

where, ${ }^{\omega_{i j}}=\left(\nabla_{i} v_{j}-\nabla_{j} v_{i}\right) / 2, G$ - shear modulus.

The material behaves in an elastic manner $(\lambda=0)$ if the von Mises condition is met:

$$
S^{i j} S_{i j} \leq \frac{2}{3} \sigma_{d}^{2}
$$

and in a plastic manner $(\lambda>0)$ if it is not met. Here, $\sigma^{d}$ - dynamic yield stress that, in the general case, can be the strain rate, pressure and temperature function. For concrete, a dependence of yield stress on pressure was considered (Belov et al., 2008):

$$
\sigma_{d}=\sigma_{s}+\frac{11.398 P}{13.9+0.82 P}
$$

If condition (7) is violated, then to find stress deviator components, a procedure of reducing to the yield circle is applied. For those purposes, $S^{i j}$ components are multiplied by the normalizing factor, which is equivalent to description of medium behavior in the plastic range by equations of the Prandtl-Reuss theory.

The limiting value of plastic strain intensity is taken as a local criterion of shear fracture in steel reinforcement:

$$
e_{u}=\frac{\sqrt{2}}{3} \sqrt{3 T_{2}-T_{1}^{2}}
$$


where $T_{1}, T_{2}-$ the first and second invariants of the strain tensor.

To describe concrete fracture, the authors use the Hoffman criterion (Hoffman, 1967; Tsai and Wu, 1971) that considers differences in ultimate tensile and compressive strength, anisotropy of strength properties:

$$
\begin{aligned}
& C_{1}\left(\sigma_{22}-\sigma_{33}\right)^{2}+C_{2}\left(\sigma_{33}-\sigma_{11}\right)^{2}+C_{3}\left(\sigma_{11}-\sigma_{22}\right)^{2}+ \\
& +C_{4} \sigma_{11}+C_{5} \sigma_{22}+C_{6} \sigma_{33}+C_{7} \sigma_{12}^{2}+C_{8} \sigma_{23}^{2}+C_{9} \sigma_{31}^{2} \leq 1
\end{aligned}
$$

where $C_{i}$ is determined as follows:

$$
\begin{aligned}
& \left.C_{1}=\left[\left(Y_{t} Y_{c}\right)^{-1}+\left(Z_{t} Z_{c}\right)^{-1}+X_{t} X_{c}\right)^{-1}\right] / 2 \\
& C_{2}=\left[\left(X_{t} X_{c}\right)^{-1}+\left(Z_{t} Z_{c}\right)^{-1}+\left(Y_{t} Y_{c}\right)^{-1}\right] / 2 \\
& \left.C_{3}=\left[\left(X_{t} X_{c}\right)^{-1}+\left(Y_{t} Y_{c}\right)^{-1}+Z_{t} Z_{c}\right)^{-1}\right] / 2 \\
& C_{4}=\left(X_{t}^{-1}-X_{c}^{-1}\right) ; C_{7}=S_{y z}^{-2} \\
& C_{5}=\left(Y_{t}^{-1}-Y_{c}^{-1}\right) ; C_{8}=S_{z x}^{-2} \\
& C_{6}=\left(Z_{t}^{-1}-Z_{c}^{-1}\right) ; C_{9}=S_{x y}^{-2}
\end{aligned}
$$

where $X_{t}, X_{c}, Y_{t}, Y_{c}, Z_{t}, Z_{c}$ - ultimate strength along $X$, $Y, Z$ axes under tension and compression, respectively, and $S_{X Y}, S_{Y Z}, S_{Z X}$ - ultimate shear strength along the corresponding axes. In case of an isotropic material $X_{t}=Y_{t}=Z_{t}=R_{t}, X_{c}=Y_{c}=Z_{c}=R_{c}$.

$S_{X Y}=S_{Y Z}=S_{Z X}=R_{S H}$

It is believed that concrete fracture under intensive dynamic loading occurs as follows (Radchenko and Radchenko, 2015):

- if strength criterion (9) is violated under compression $\left(\mathrm{e}_{\mathrm{KK}} \leq 0\right)$, then the further behavior of the material is described by the hydrodynamic model $\sigma_{i j}=-P$;

- if criterion (9) is violated under tension $\left(e_{\mathrm{KK}}>0\right)$, then the material is considered to be completely fractured and stress tensor components are taken to be equal to zero.According to experimental results, dynamic loading leads to improvement of concrete strength characteristics. It should be noted that the dependence of the ultimate tensile strength on the strain rate and the dependence of the ultimate compressive strength on the strain rate are different. The ratio between the static and dynamic ultimate strength can be represented by a dynamic response factor: $K_{d}=R_{d} / R_{s}$ where $R_{d}-$ dynamic strength, $R_{s}$ - static strength.

Based on experimental data (International Atomic Energy Agency, 2015), approximation dependences for dynamic response factors of concrete under compression (10) and tension (11) were plotted. The corresponding dependence curves of $K_{d}$ versus the strain rate (in s-1) are given in Figure 1, where curve 1 describes a dependence of the dynamic response factor under tension, and curve 2 - under compression.

$$
\begin{aligned}
& K_{d t}=0.00158333 e^{5}+0.0252855 e^{4}+0.15255 e^{3}+0.47898 e^{2}+ \\
& +1.01959 e+2.36037 \\
& K_{d c}=0.000832308 e^{5}+0.0110547 e^{4}+0.0447734 e^{3}+0.0475887 e^{2}+ \\
& +0.0184316 e+1.20895
\end{aligned}
$$

To find the ultimate shear strength of concrete, ratio

(Belov et al., 2008) $R_{s h}=0.55 \sqrt{R_{c} R_{t}}$ is used, where $R_{c}-$ compressive strength, $R_{t}-$ tensile strength. The materials had the following basic characteristics: concrete: $\rho=2,450 \mathrm{~kg} / \mathrm{m}^{3}$, Poisson's ratio $v=0.2, R_{t}=1.75 \mathrm{MPa}$, $R_{c}=22 \mathrm{MPa}, G=10.8 \mathrm{MPa}, \sigma_{\mathrm{s}}=7.7 \mathrm{MPa}$; fiber-reinforced concrete: $\rho=2,450 \mathrm{~kg} / \mathrm{m}^{3}$, Poisson's ratio $\nu=0.2$, $R_{t}=3.4 \mathrm{MPa}$, compressive strength $R_{c}=41 \mathrm{MPa}, G=17.1$ $\mathrm{MPa}, \sigma_{\mathrm{s}}=7.7 \mathrm{MPa}$; steel: $\rho=7,850 \mathrm{~kg} / \mathrm{m} 3$, Poisson's ratio $v=0.3, \quad G=78.5 \mathrm{MPa}, \sigma_{d}=390 \mathrm{MPa}$.

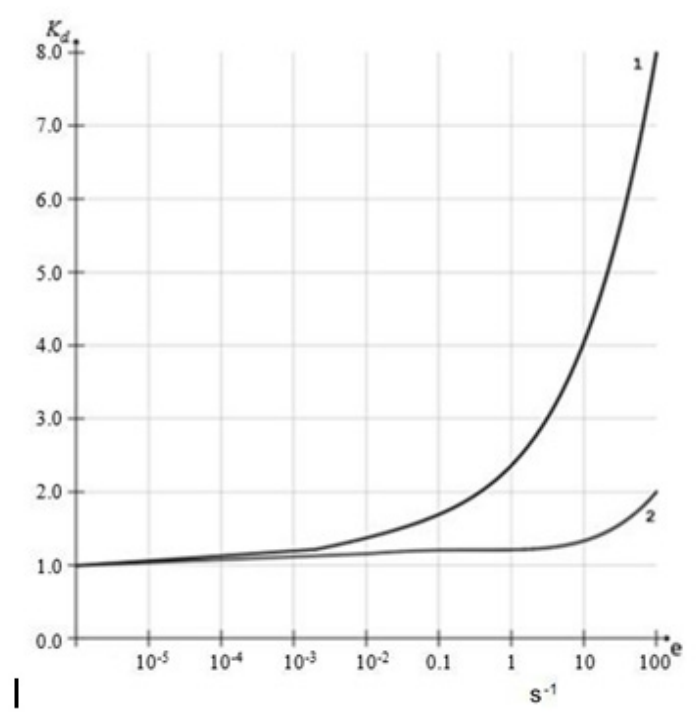

Figure 1. Dependence of steel strengthening on the strain rate

\section{Discussion}

In order to determine the stress-strain state, crack formation and fracture processes, the authors conducted studies on behavior of three-layer fiber-reinforced concrete beams under dynamic loading. The beams under study had three layers in a cross section: the upper and lower layers were of fiber-reinforced concrete with concrete in the middle. The experimental studies were performed using a pile driver imposing short-term dynamic loading.

The test specimens had a length of $2.2 \mathrm{~m}$, distance between the centers of bearing $-2 \mathrm{~m}$, cross-section dimensions $-0.22 \times 0.15 \mathrm{~m}$. Each test specimen had three layers in a cross section: the upper and lower layers were $20 \mathrm{~mm}$ thick and had carbon-fiber reinforcement, and the middle layer of concrete was $110 \mathrm{~mm}$ and had metal reinforcement. The carbon fiber volume fraction in the upper and lower layers was $0.2 \%$.

In the middle layer, $8 \varnothing 10$ A400 reinforcement was placed. It was supported by wire ( $\varnothing 4$ B500) stirrups. The fiber-reinforced concrete layers were reinforced with a tied mesh ( $\varnothing 4$ B500 wire, mesh spacing $-66 \mathrm{~mm}$ ).

To measure the load and deflection of the test specimens, a system of primary transducers of measurement data was used.

The value of dynamic load under short-term impact was determined using a dynamometer gauge. To 
determine specimen displacements, linear displacement transducers were used. Accelerations were measured using accelerometers.

To determine concrete and fiber-reinforced concrete deformations, resistive strain gauges (PKB-20 and PKB50 (constantan alloy, paper base)) were placed on the surface of the test beams.

Reaction at the supports was measured using dynamometers. A falling weight of $450 \mathrm{~kg}$ was dropped on the beams from a height of $0.7 \mathrm{~m}$ with the help of a bomb-dropper.

In the course of the studies, the following was established: beam fracture occurs along the section, which is orthogonal to the longitudinal axis, with crack formation in the area of pure bending (Figure 2). The ultimate load resulting in concrete element fracture Fud was equal to $120 \mathrm{kN}$.
In mathematical modeling, contact action of the falling weight was replaced by an impulse load determined experimentally (Figure 3 ).

Numerical modeling was performed with clear defining of reinforcement, i.e. contact interaction between concrete and metal reinforcement was considered. Formation of contact and free surfaces in concrete and fiber-reinforced concrete upon crack formation and fragmentation was taken into account as well. Concrete and fiber-reinforced concrete behavior is described by equations (1)-(11) with strength criterion (9).

Behavior of the steel reinforcement mesh was described by the elastic-plastic model (6), (7). A structural design and reinforcement details were specified in accordance with the experimental design (Figure 4). The structure was divided into finite elements - tetrahedra. The total number of finite elements in calculations amounted to $1.8 \times 10^{7}$.

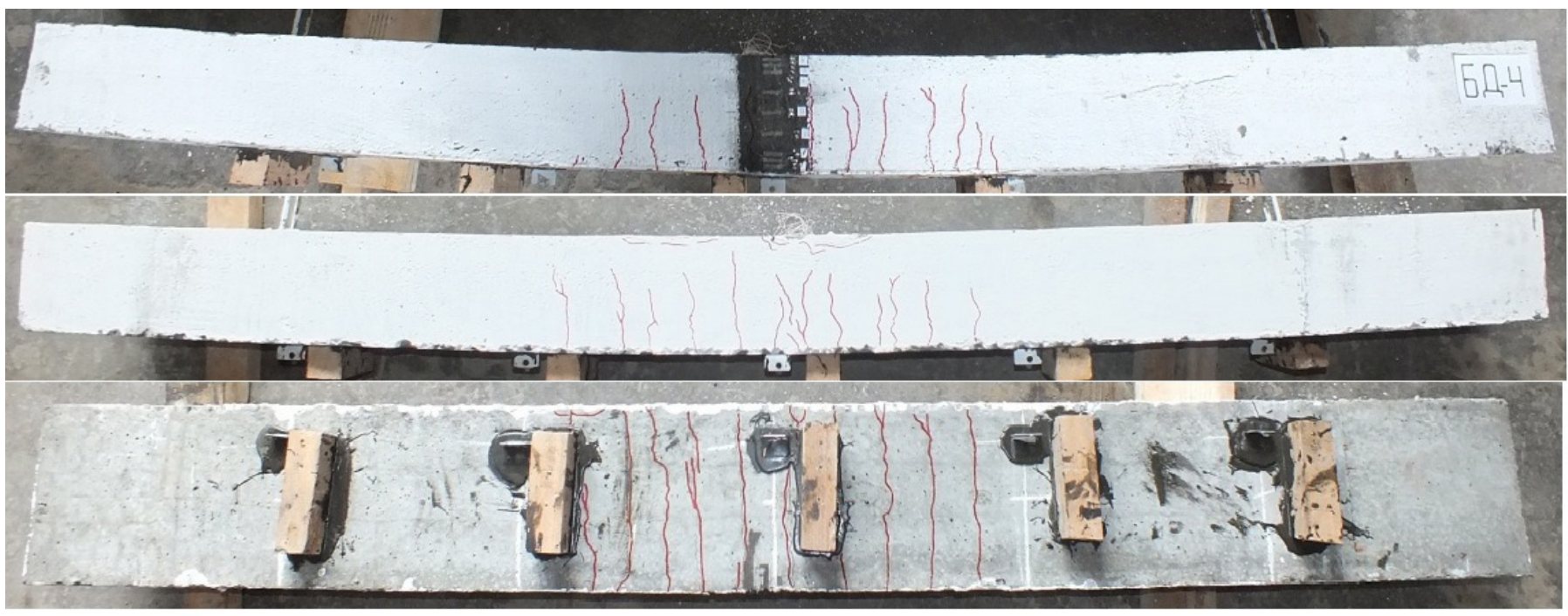

Figure 2. Concrete beams after loading during the experimental study

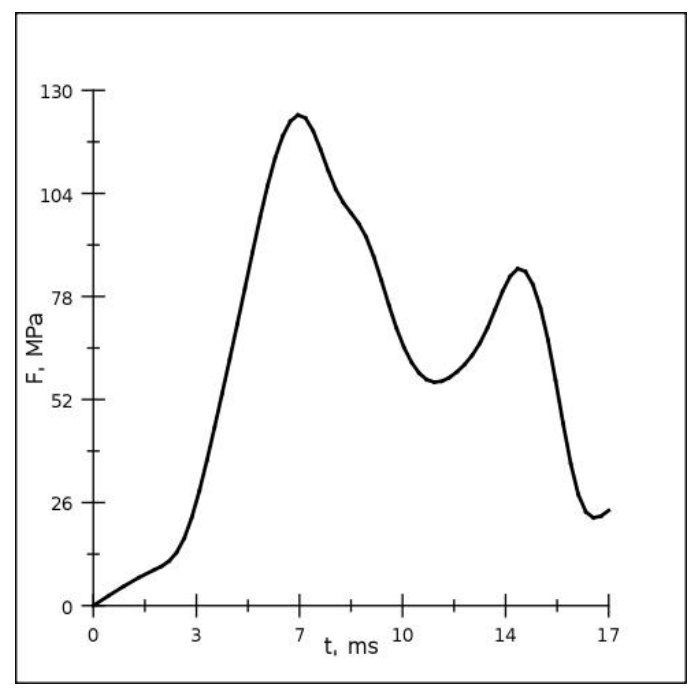

Figure 3. Load dependence on time 
To implement the structural design and evaluate the influence of reinforcement on the material fracture pattern, numerical studies on impact fracture of a laminated beam without a reinforcement layer were conducted.

Figures 5 and 6 show results of the numerical studies on a three-layer beam without reinforcement (a) and with reinforcement (b) under impact loading at different periods of time. It is clear that patterns of crack formation and fracture in beams with reinforcement and without it differ significantly. In the beam without reinforcement, main cracks generate on the back surface under the area of load application. Those cracks lead to beam fragmentation into three pieces (Figure 6a). In the beam with reinforcement, cracks propagate along the entire specimen and its total destruction is less. Maximum stresses in the beam are observed in the areas adjacent to metal reinforcement. Concrete fracture is caused by occurring fracture tensile and shear stresses in the areas of contact between concrete and the reinforcement mesh. That results in crack formation and further stress relaxation in concrete that was not fractured.

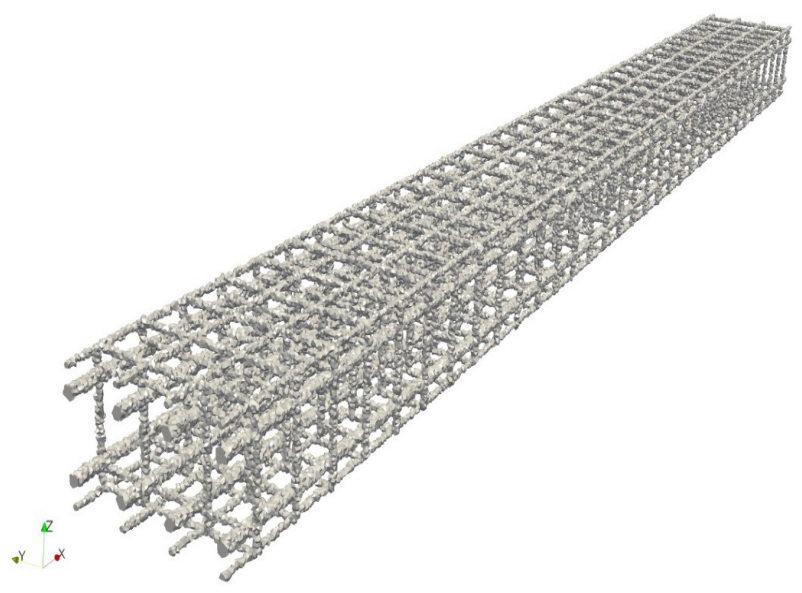

Figure 4. Structural design of beam reinforcement

Figure 7 shows comparison of experimental (solid curve) and numerical (dashed curve) changes over time in displacement of back surface points in a reinforced-concrete beam. Divergence was $12 \%$. Agreement with the experimental data is satisfactory.
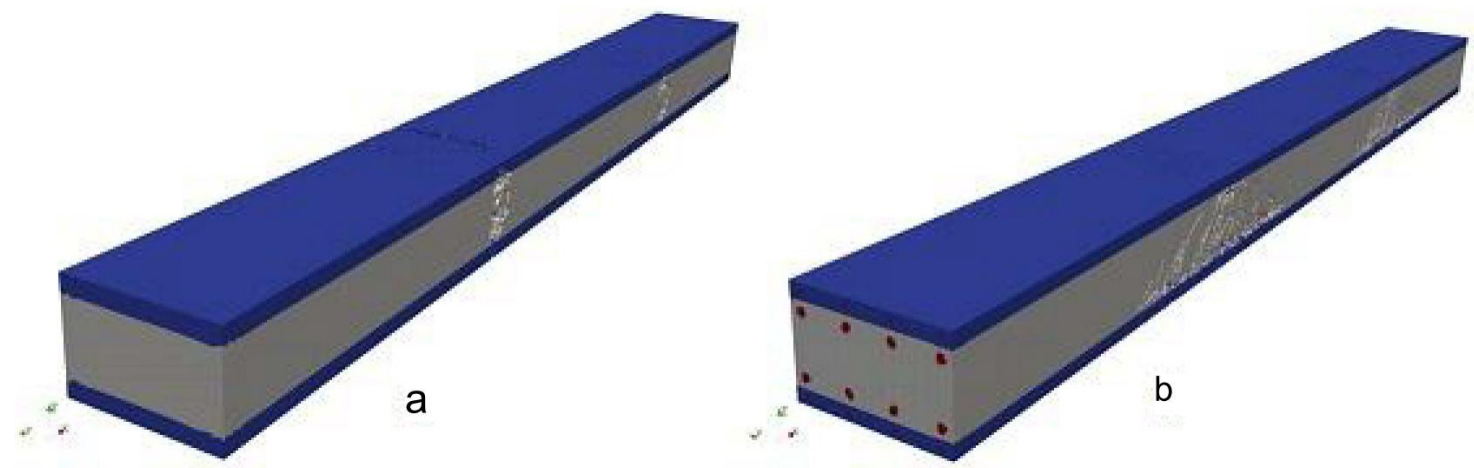

Figure 5. Computational configurations of a three-layer beam without reinforcement (a) and with reinforcement $(b)(t=3 \mathrm{~ms})$
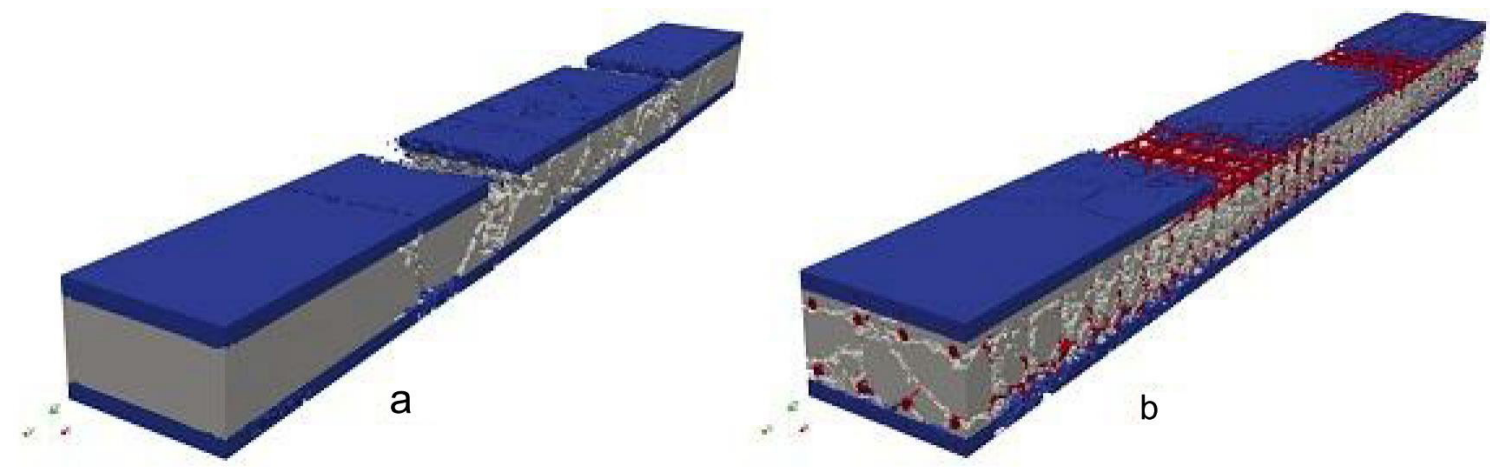

Figure 6. Computational configurations of a three-layer beam without reinforcement (a) and with reinforcement $(b)(t=6 \mathrm{~ms})$ 


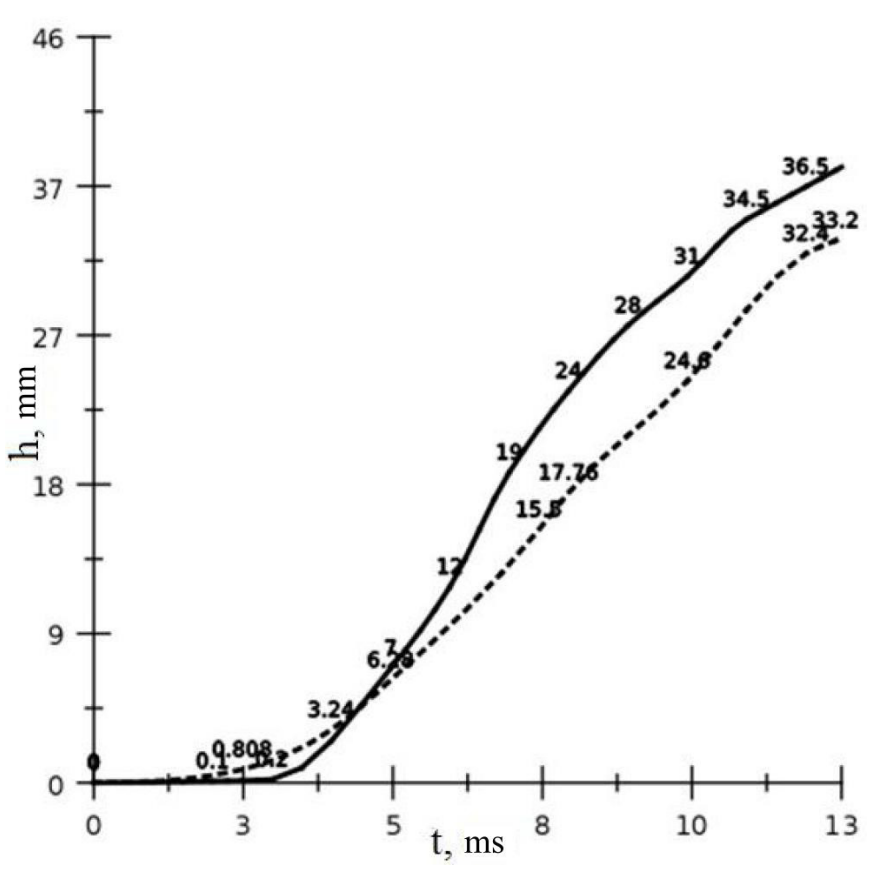

Figure 7. Displacement of points on the beam back surface over time

\section{Conclusions}

As a result of the conducted experimental and numerical studies, the following conclusions can be made:

1. The model of concrete and fiber-reinforced concrete behavior, considering bimodularity with regard to strength characteristics, plastic properties, and relations between strength and strain rate, was suggested.

2. The developed calculation algorithm and procedure make it possible to analyze and predict behavior of actual structures in a full dynamic 3D setting with account for material fracture and structure fragmentation, formation of contact and free surfaces.

3. Fracture dynamics in concrete beams reinforced with metal bars was studied. Good agreement of the results with the experimental data was observed.

The study was performed with support from the Russian Foundation for Basic Research (grants No. 1841-703003 and No. 18-48-700035). 


\section{References}

Anderson, C.E., Cox, P.A., Johnson, G.R., Maudlin, P.J. (1994). A Constitutive Formulation for Anisotropic Materials Suitable for Wave Propagation Computer program-II. Computational Mechanics, 15, pp. 201-223.

Belov, N.N., Kabanzev, O.V., Kopanitsa, D.G., Yugov, N.T. (2008). Calculative-experimental method to analyze dynamic strength of the construction elements made of reinforced concrete. Tomsk: STT, $292 \mathrm{p}$.

Buzyurkin, A.E., Kraus, E.I., Gladky, I.L. (2015). Determination and verification of Johnson-Cook model parameters at highspeed deformation of titanium alloys. Aerospace science and technology, 45, pp. 121-127. DOI: 10.1016/j.ast.2015.05.001.

International Atomic Energy Agency (2018). Safety Aspects of Nuclear Power Plants in Human Induced External Events: Assessment of Structures, Safety Reports Series, 87. Vienna: IAEA, 204 p.

Johnson, G.R. (1977). High velocity impact calculations in three dimension. Journal of Applied Mechanics, 44 (1), pp. 95-100.

Johnson, G.R. (1977). Three-dimensional analysis of sliding surface during high velocity impact. Journal of Applied Mechanics, 44 (6), pp. 771-773.

Hoffman, O. (1967) The brittle strength of orthotropic materials. Journal of Composite Materials, 1, pp. $200-206$.

Radchenko, P.A., Batuev, S.P., Radchenko, A.V. (2014). 3D modeling of deformation and fracture in heterogeneous materials and structures under dynamic loading (EFES 1.0). Federal Service for Intellectual Property, Patents and Trademarks. Certificate of computer program state registration No. 2014614671. Registered in the Register of Computer Programs on May 6, 2014.

Rachenko, A.V., Radchenko, P.A. (2015). Shock wave processes and fracture in anisotropic materials and structures. Tomsk: Tomsk State University of Architecture and Building, 204 p.

Radchenko, P.A., Batuev, S.P., Radchenko, A.V., Plevkov, V.S. (2015). Numerical simulation of deformation and fracture of space protective shell structures from concrete and fiber concrete under pulse loading. Omsk Scientific Bulletin, 3, pp. 345-348.

Sedov, L.I. (1973). Continuum mechanics. Vol. 1. Moscow: Nauka, 536 p.

Tsai, S.W., Wu, E.M. (1971). A General Theory of Strength for Anisotropic Materials. Journal of Composite Materials, 5, pp. 58-80. 


\title{
МОДЕЛИРОВАНИЕ РАЗРУШЕНИЯ АРМИРОВАННЫХ БЕТОННЫХ КОНСТРУКЦИЙ ПРИ УДАРЕ
}

\author{
Andrey Radchenko1, Pavel Radchenko², Stanislav Batuev ${ }^{3}$ Vasiliy Plevkov ${ }^{4}$ \\ 1,2,3,4 Tomsk State University of Architecture and Building \\ 2 Solyanay Sq., Tomsk, Russia, 634003
}

${ }^{1}$ Corresponding author: andrey-radchenko@live.ru

\begin{abstract}
Аннотация
Введение: В работе представлены результаты комплексного экспериментального и численного исследования поведения железобетонных балок при импульсных нагрузках. Балка состояла из трех слоев: материал верхнего и нижнего слоя - фибробетон, с объемной долей углеродной фибры 0.2\%. Материал среднего слоя - бетон с металлической арматурой. Методы: Экспериментальные исследования проводились на копровой установке. Груз весом 450 кг сбрасывался на балку с высоты 0.7 м. Численные исследования проводились методом конечных элементов в полной трехмерной динамической постановке с использованием в авторского программного комплекса EFES, учитывающий фррагментацию конструкций, образование новых контактных и свободных поверхностей. Результаты: Арматурная сетка при численном моделировании выделяется явным образом. Исследовано изменение во времени напряженно-деформированного состояния и разрушение железобетонных балок при кратковременных ударных нагрузках. Разработан алгоритм и методика расчета позволяющие исследовать и прогнозировать поведение реальных конструкции в полной трехмерной динамической постановке Предложена модель поведения бетона и фибробетона, учитывающая анизотропию, разномодульность прочностных свойств, пластические свойства и зависимость прочности от скорости деформации и давления. Исследована динамика разрушения бетонных балок, армированных металлическими стержнями. Проведено сравнение с экспериментальными данными, показавшее хорошее согласование результатов.
\end{abstract}

Ключевые слова: модель, разрушение, деформация, напряжение, бетон, фибробетон. 